\title{
O capitalismo pós-nacional e os riscos da inserção desigual do Brasil
}

\author{
JOSÉ VICENTE DA SILVA LESSA
}

Percebida neste final de século como a macrotendência histórica a conformar o futuro dos povos, a globalização econômica não chega a ser um fenômeno novo. Suas grandes linhas já se vinham prenunciando ao longo de todo o século XX, enquanto que algumas das suas raízes se pode facilmente buscar no século XIX. Nas últimas duas décadas deste último, a exacerbação da corrida colonial e imperialista das grandes potências já exprimia o “ímpeto” do capitalismo para integrar ao conceito de mercado áreas geográficas cada vez maiores. Remontam também ao século passado a formação de algumas corporações multinacionais, bem como um certo internacionalismo capitalista, expresso na proliferação de acordos comerciais, e socialista, que pretendia, desde então, "globalizar” a produção pela integração mundial da classe operária.

Duas grandes guerras marcaram, na centúria que ora termina, a exaustão do velho sistema de economias fechadas, competindo por domínios coloniais, zonas de "co-prosperidade" e "espaços vitais". Enquanto as fronteiras econômicas das nações industriais tradicionais e emergentes coincidiram com suas fronteiras políticas, a expansão de mercados, condição essencial do empreendimento capitalista, impôs a essas nações uma política imperialista agressiva, formadora de zonas internacionais de exclusão, seja pela posse de um império colonial, pela manutenção de esquemas preferenciais com nações periféricas (dos quais é a Commonwealth britânica o exemplo mais completo), ou pelo recurso extremado da guerra orientada ao estabelecimento de áreas de domínio ou influência.

Dos escombros da Segunda Guerra nasce, contudo, uma autêntica nova ordem, onde o capital aos poucos se transnacionaliza e os espaços econômicos se integram. A nova clivagem política do mundo em "esferas” de confrontação ideológica irá beneficiar a acumulação capitalista, à medida que permitirá justificar investimentos estatais maciços em tecnologias militares, cuja reversão para o emprego civil insufla, ainda hoje, a notável verticalização tecnológica deste século.

A globalização propriamente dita viria a completar-se no desmonte do bloco socialista e conseqüente "triunfo" dos princípios do mercado em praticamente todos os quadrantes do planeta. O vago emprego cotidiano do termo, no entanto, dificulta avaliação mais precisa de seu alcance e de suas implicações. Por esta razão, optamos neste ensaio pelo termo capitalismo pós-nacional, que acreditamos possua propriedades heurísticas superiores. Trata-se de exprimir, em um conceito, 
a formação histórica sucessora dos “choques imperialistas” da fase anterior - e da qual é a Guerra Fria, em um certo sentido, desdobramento tardio.

\section{O papel das multinacionais}

A transição do capitalismo, por assim dizer, "imperial” para o "global” ou pós-nacional tem como elo central as corporações multinacionais, várias das quais já despontavam como agentes privados das políticas nacionais expansionistas no século XIX. Data da segunda metade do século passado, ou mesmo de antes, a fundação de vários gigantes mundiais: Siemens (1847), Westinghouse (1869), General Electric (1882), AEG (ca. 1880), agentes de uma disputa transatlântica pela preeminência nos ramos elétricos, eletrônico e mecânico. $\mathrm{O}$ acirramento das disputas imperialistas nos anos que antecedem 1914 reforça, na atuação dessas corporações, práticas consentâneas com as políticas de governo. (A possível exceção dos Estados Unidos, que já dispunham de legislação antitruste em fins do século XIX, se explica mais como defesa de interesses econômicos internos que como a tentativa de limitar a ação internacional de suas empresas).

O esforço produtivo das duas guerras mundiais beneficiou corporações já dominantes em áreas estratégicas, como as indústrias elétrica, eletrônica e de telecomunicações (beneficiária direta da tecnologia do radar), química, petrolífera, siderúrgica e outras menos estratégicas (mecânica, indústria naval e de material de transportes). Como saldo da Segunda Guerra, inúmeras pequenas concorrentes são absorvidas pelas corporações maiores, do que resulta concentração sem precedentes da produção industrial. Investimentos tecnológicos da guerra alimentam a disputa pelo controle de processos industriais (formação de pools de patentes), acentuando-se o caráter monopolista ou oligopolista das multinacionais, e dão início a novos e promissores ramos industriais.

No contexto da nova ordem, inaugurada com a Carta de São Francisco, os governos renunciam a todo tipo de expansionismo militar. Não obstante, suas empresas estão livres para perseguir, com maior eficácia, os efeitos econômicos dessa mesma política. Mudam as formas internacionais de atuação para dar vazão ao "ímpeto globalizante" do empreendimento capitalista. Ao transnacionalizar-se, emancipa-se o capital da proteção política dos governos. Seus interesses globais já não precisam “contaminar” a ação política, o que permite um longo período de paz global. Persiste ainda a cultura ideológica da fase anterior - a era dos embates imperialistas. A conseqüente percepção da "insegurança coletiva” reforça a idéia da "inevitabilidade" da guerra, ancorada na lógica mecanicista da "balança de poder”. Na prática, essa cultura ideológica e sua expressão militar - a corrida armamentista - favorecem o desenvolvimento de inúmeras novas indústrias, de que são a informática, a tecnologia do laser e os novos materiais alguns exemplos. 
Atores centrais da ordem econômica global, as multinacionais avançaram nas últimas décadas sobre praticamente todos os ramos industriais, e têm participação crescente no setor de serviços (comunicações, entretenimento, finanças) e de infraestrutura. Seu modus operandi é amplamente conhecido. Alocam recursos de capital para produzir diretamente no mercado consumidor ou em área situada em função desse mercado, combinando mão-de-obra e outras facilidades locais. Ao produzir diretamente no mercado consumidor, põem-se a salvo dos custos de exportação, de injunções burocráticas do comércio exterior, das flutuações do câmbio, da duplicidade de regimes fiscais e demais incertezas associadas ao mercado internacional. Suas operações de comércio exterior processam-se, basicamente, entre suas próprias unidades, o que lhes permite controlar cada operação na origem e no destino. Ao colocar-se, por esta via, fora do modelo tradicional de operação de comércio exterior, assumem essas empresas vantagens competitivas absolutas. Assim, apesar de a grande difusão de novas tecnologias permitir hoje margem de ação a pequenos empreendimentos, atuando de forma articulada entre si, as zonas internacionais de exclusão formadas pelos conglomerados multinacionais em áreas produtivas nobres, persistem, como regra, no limiar do século XXI.

\section{O componente tecnológico}

Globalização, como hoje a entendemos, denota a maturação do capitalismo pós-nacional que, com a abertura dos espaços econômicos do Leste europeu, da Rússia e da China, assume o aspecto de uma vasta integração mundial de mercados. Assiste-se à "vitória" do liberalismo, enquanto mais e mais nações passam a professar os princípios da economia de mercado na Ásia e na América Latina.

O capitalismo pós-nacional é, contudo, mais que a ordem mundial globalizada. Igualmente determinante na nova formação histórica é a verticalização do progresso tecnológico, princípio, por excelência, da acumulação do capitalismo pós-nacional, obtida com o decisivo apoio das políticas de governo. Essa verticalização se faz de duas formas: pelo progresso técnico (aperfeiçoamento continuado dos meios tecnológicos de produção) e pela incorporação tecnológica (inovação tecnológica pela agregação do saber ao produto final).

Nos anos 50 e 60, os países industriais vivenciaram vigorosa arrancada econômica, resultante da acelerada substituição de máquinas nas fábricas. Entre 1952 e 1973, os meios de produção mais que duplicaram em relação à mão-deobra disponível. Em grande parte, esse progresso decorre da conversão de tecnologias militares à produção civil. Ao final do boom, a estrutura produtiva dos países industriais, como apontam Glyn et al (In Capitalism Since World War II. Fontana: Londres, 1984), pouca semelhança guardava com aquela de duas décadas atrás. Os gastos norte-americanos com a Segunda Guerra têm prosseguimento 
em sua renúncia à desmobilização militar após a Guerra da Coréia (1953), passando, ao longo dos anos 60 e início dos 70, pela Guerra do Vietnã e, desde então, até 1990, no confronto direto com a União Soviética. Subsidiariamente, concorrem as tecnologias desenvolvidas nos programas de exploração espacial.

O spin-off dos programas estatais de tecnologia intensiva acarretam vantagens extraordinárias aos agentes econômicos privados norte-americanos e de seus grandes parceiros da OTAN. Os governos investem, assim, maciçamente em pesquisa militar e espacial, cujos produtos encontram, eventualmente, aplicação civil e são repassados à indústria. A conveniência desse método de socialização dos custos de $P \& D$ enseja a formação de interesses constituídos nas grandes corporações que, mediante a compra de patentes, incorpora o conhecimento assim gerado como patrimônio seu. Pouca chance efetiva têm os países chamados "em desenvolvimento" de acesso a essas tecnologias, senão sob contrato de licenciamento ou como componente de produtos finais.

\section{Fim do ideal mercantilista?}

Ao abarcar mais e mais áreas produtivas nobres, em virtude de sua superioridade tecnológica e das facilidades operacionais de que desfrutam, tenderiam as multinacionais a consolidar e ampliar zonas internacionais de exclusão produtiva, com a conseqüente marginalização de produtores nacionais. A facilidade com que direcionam seus fatores de produção para os mercados consumidores tenderia, ademais, a tornar obsoleto, em escala mundial, o "grande" comércio de manufaturas. Duas seriam as possíveis exceções: itens de consumo de baixo valor agregado, produzidos por países com mão-de-obra abundante que desejem aceder ao mercado mundial, e itens de alto conteúdo tecnológico (equipamentos e artigos de tecnologia de ponta, bens de capital e instrumentos especializados). Em uma grande faixa intermediária não se justificariam os custos associados ao comércio exterior, em face da concorrência estabelecida diretamente no mercado consumidor. A possível exceção a esta regra seriam as zonas de integração de mercado, à medida que possam elas executar políticas deliberadas de desvio de comércio. Na prática, essas áreas constituiriam um comércio "nacional” ampliado. No contexto mundial, no entanto, estreita-se o espaço disponível a exportação de manufaturas por empresas nacionais, frustrando-se, em parte, a promessa liberalizante da globalização.

A ordem mundial globalizada é essencialmente diferente daquela que poderia ter sonhado um livre-cambista vitoriano, inspirado nas teses da divisão internacional do trabalho e das vantagens comparativas. É certo que a estratégia exportadora continuaria a ser, no século XX, a origem da riqueza das nações especialmente as asiáticas (Japão, Taiwan, Coréia do Sul e, mais recentemente, China). Mas essa política exportadora - de natureza às vezes agressiva - obedeceu a um "plano" maior, deliberado ou não, que a história se incumbiria de revelar, 
voltado a uma espécie de “acumulação primitiva”, uma etapa do desenvolvimento que, como tal, não se esgota em si mesma. O objetivo de uma tal política vai além da constituição de um setor exportador competitivo. Trata-se da formação do "grande capitalismo" nacional - a formação de grandes holdings industriais destinadas a atuar mundialmente.

A ordem mundial globalizada do século XXI pode, portanto, conduzir a certa relativização da importância do comércio internacional de manufaturas. Os custos de produção e conseqüentes vantagens relativas serão determinados, antes, pela capacidade de realocação espacial da produção, em escala global, que pelos ganhos de eficiência de produtores nacionais isolados. A onipresença de unidades industriais interligadas sob a mesma matriz, associadas às tecnologias avançadas da informação já seriam suficientes para operar ampla revisão da relação empresamercado. Os processos automatizados de produção podem, por exemplo, ganhar dimensão nova se lhes forem agregados os recursos de comunicação cibernética à distância. Uma revolução na tecnologia dos materiais poderá, ademais, dispensar certos insumos básicos industriais como o ferro e o aço, assim como no passado a resina sintética deslocou a borracha natural do mercado e a fibra ótica, o cobre. O deslocamento físico de mercadorias pelos sete oceanos estaria, mais e mais, limitado a algumas commodities sem substitutos, equipamentos e bens de capital de alta agregação tecnológica, cuja produção especializada não demande escala. Em uma tal conjuntura, seria praticamente impossível a um país “exportador” diversificar ou elevar qualitativamente sua pauta de produtos.

A ordem econômica global ou do capitalismo pós-nacional implicaria, nesta hipótese, o fim do "grande" comércio mundial. O primado das trocas comerciais daria lugar à internacionalização da empresa e da produção, que se pode hoje administrar à distância, e aos deslocamentos instantâneos de capitais, no ritmo da comunicação cibernética. Em síntese, sendo o mercado "global” um só, exigir-seiam empresas onipresentes.

Estratégias de inserção dos "emergentes"

Enquanto no Brasil se tem a corporação multinacional como anátema aos interesses nacionais, países do extremo oriente e do sudeste asiático demonstraram ser possível promover tais interesses pela adesão aos mesmos métodos de ação do "grande capitalismo". A estratégia japonesa, por exemplo, dirigiu-se, em seus primórdios, à formação desses consórcios. Outros fatores tiveram igual importância: a imigração de poupanças da China e da Indochina para o Japão e para os futuros “tigres”, em virtude da longa turbulência política e da proteção política, financeira e econômica americana (britânica no caso de Hong Kong). No entanto, sem uma política deliberada de promoção do "grande capital” é pouco provável que tal estratégia de desenvolvimento industrial tivesse frutificado. 
Taiwan merece consideração à parte. Em que pese a falta de dados estatísticos, é sabido que a transferência do Kuomintang para a ilha se fez com maciça transferência de capitais que propiciaram a formação, em Formosa, de importante praça financeira. Embora sem constituir grandes corporações, Taiwan notabilizou-se pelos investimentos no exterior e pela criação de uma rede de manufaturas de baixo custo para exportação. Tratava-se do mesmo princípio da “acumulação primitiva” observado no Japão. Superada essa "fase”, aproveita a ilha essa mesma rede para montar produtos de consumo de elevada agregação tecnológica (computadores, material ótico e fotográfico, bens de capital etc.) pela integração vertical de pequenos produtores especializados. Como estratégia, a fabricação de manufaturas de baixo custo para exportação serve hoje aos propósitos da China, a qual, seguindo o mesmo modelo, está reestruturando estatais selecionadas para atuar como corporações globais.

Em vista destes exemplos, restaria indagar: quais as possibilidades de inserção competitiva do Brasil às novas realidades da economia mundial no século XXI? Ou, talvez, a questão pudesse ser: que estratégia de articulação à economia mundial servirá melhor ao Brasil? Inúmeros fatores têm sido apontados como "empecilhos" nas atuais circunstâncias (custo Brasil, taxas de juros, educação etc.) - condições que, por seu caráter conjuntural, ou que por se tratar de temas sobre os quais há elevado consenso, não serão aqui consideradas. Quatro fatores restritivos endógenos devem, contudo, ser destacados: a) o caráter patrimonialista da ação empresarial; b) a ausência de tradição científica e de investimentos em P\&D; c) o predomínio de um pensamento microempresarial; e d) a ausência de uma política de desenvolvimento industrial de longo prazo.

O patrimonialismo na organização empresarial constitui traço cultural próprio do Brasil e da América Latina. Nesse contexto cultural, a empresa é, antes de tudo, vista como um "negócio de família” e não como um agente produtivo de responsabilidade social. Em uma economia desenvolvida de mercado, porém, o comportamento empresarial obedece ao imperativo da estrita profissionalização de seus quadros dirigentes, transformando a figura tradicional do capitalista na do "funcionário do capital”. As habilidades requeridas dessa burocracia privada incluem a permanente busca de adaptação a injunções históricas, necessariamente cambiantes, de modo a colocar-se a empresa em competição ativa com o universo empresarial. A inovação e a internacionalização vêm a ser os imperativos básicos da competição de mercados, o que exige das firmas maiores taxas de formação de capital produtivo fixo, pela abertura de seu capital acionário e pela profissionalização de seus quadros dirigentes.

O traço patrimonialista da empresa brasileira conspira, contudo, contra essas metas ou mesmo as exclui. Subjaz a este fenômeno uma questão conceitual complexa, ou seja, a de definir a empresa como entidade privada de responsabilidade pública. À medida que mobiliza recursos da sociedade para 
atender demandas dessa mesma sociedade, a empresa assume responsabilidades que não cabem mais na esfera restrita do arbítrio pessoal. O empreendimento de capital aberto, a sociedade de participação por quotas, o gerenciamento profissional devem, à medida que o empreendimento cresça, garantir que os rumos da empresa não se submeterão incondicionalmente aos desígnios pessoais de seus "donos", mas a uma perspectiva de interesse coletivo.

Inserido em um contexto social e histórico, o empreendimento capitalista deve atentar para os efeitos de médio e longo prazos de sua ação sobre o conjunto da sociedade e suas formas de condução precisam ser revistas e discutidas. Submetida ao controle exclusivo de seus fundadores, a empresa nacional tem sido, contudo, impedida de assumir dinamismo e latitude próprias ao empreendimento capitalista. O empreendimento mantém-se nos estritos limites nacionais; o empresariado permanece provinciano, enquanto se desperdiçam oportunidades históricas.

A ausência de tradição científica refletiria a base agroexportadora que deu suporte à formação econômica do país, e cujas oligarquias, convencidas da “irrenunciável” vocação agrícola brasileira, privilegiaram formas bacharelescas de educação, acomodando-se à idéia de modernização passiva pela introdução gradual de inovações industriais geradas em países industriais avançados. Nesse contexto, a educação tem sido citada como a “questão-chave” do desenvolvimento, embora sem os devidos cuidados e qualificações. Em verdade, a simples universalização do ensino não garante a constituição de uma economia mais inovadora ou a formação de uma burguesia industrial cosmopolita. Para tanto, deve a educação estar primordialmente voltada "à livre busca do espírito" que caracteriza a atividade científica, e medrar em um ambiente cultural e institucional favorável à inovação. Sem uma base cientifica sólida, exclui-se da cultura empresarial a inovação tecnológica, o interesse por produtos novos e a própria busca de soluções rentáveis de baixo custo. O país se torna tributário de inovações feitas alhures, renuncia a importante mecanismo de capitalização e mantém ritmo reflexo de desenvolvimento.

A ascendência do pensamento microempresarial atrelado ao imperativo da geração de empregos conspira, igualmente, contra o fortalecimento da base empresarial, à medida que desvia a ênfase das políticas brasileiras para unidades produtivas com baixa capacidade de investimento e pouca margem de atuação em bases seguras e regulares no mercado mundial. A prevalecer essa tendência, resulta limitada a capacidade da burguesia nacional investir na indústria pesada, em setores de base e no desenvolvimento tecnológico. Não se trata aqui, decerto, de negar a importância do pequeno empresariado como provedor de empregos e como contribuinte para a formação do PIB. Deve-se, entretanto, alertar para os riscos da adoção de um "modelo" microempresarial como base ou padrão de desenvolvimento nacional, em detrimento de uma desejável - ainda que pouco 
compreendida - "grande burguesia” nacional. (Note-se que a possível rejeição nacional a essa "grande burguesia" decorre do estilo patrimonialista de gestão da empresa nacional, que permite associar o "grande grupo econômico" diretamente a pessoas, e não a entidades de razão social.)

Uma alternativa a este quadro seria a integração horizontal de pequenas e médias empresas especializadas em cadeias produtivas maiores, ligadas a "montadoras" que possam oferecer produtos sob encomenda de alto valor agregado. Esse modelo de descentralização e de integração industrial, tal como adotado em Taiwan, não se encontra, aparentemente, em cogitação no Brasil. No contexto de uma política desarticulada de promoção da PME, em nome apenas do emprego, muito pouco se terá agregado ao imperativo do aumento da poupança interna e, menos ainda, ao da inserção competitiva no capitalismo global.

Essa observação conduz ao quarto fator restritivo endógeno, no Brasil, à inserção internacional competitiva: a ausência de uma estratégia de desenvolvimento industrial a longo prazo. A opção assumida nos anos 50 de fomento industrial pela importação de poupanças, aliada à crença nos poderes ilimitados do mercado, coibiu o desenvolvimento de uma política mais fecunda de planejamento que implicasse a equiparação de seu parque industrial ao das economias mais avançadas. Nos exemplos asiáticos mencionados, sugere-se que a ascensão, ainda que tardia, ao "grande capitalismo" é a forma mais consistente de inserção mundial competitiva. Não obstante, ao "optar” por uma política que privilegia a pequena e média empresa e a importação de poupanças, assume o país os riscos associados a um "modelo" jamais testado com êxito no mundo.

\section{Conclusões}

No capitalismo pós-nacional, a realização do potencial econômico de uma nação passa necessariamente pela questão da inserção externa. Será, por conseguinte, importante indagar o que precisamente é essa etapa histórica do capitalismo, quais as formas possíveis de "inserção" nacional e o que vem a ser seu caráter "competitivo". O conceito de capitalismo pós-nacional exprime claramente o fato de que o locus da atuação das firmas capitalistas não é mais, tipicamente, o espaço nacional, mas o mercado global. Não obstante, o conceito deve também exprimir o conteúdo semântico de “capitalismo" enquanto categoria histórica. Tal implica perceber que essa forma genérica de organização econômica dos povos é, fundamentalmente, um sistema de relações dinâmicas em lenta mas permanente transformação. Sua essência está, sobretudo em sua atual fase "global”, na inovação tecnológica, que permite o progresso técnico, a incorporação de valor e, em suma, a acumulação, a capitalização ou a formação da riqueza.

Segue-se que a inserção internacional não será competitiva se não for dinâmica; ou seja, deve ela recusar as condições mundiais de competitividade 
como permanentes; e, para ser dinâmica, deve ela ser transformadora, capaz de criar fatos novos e de liderar certos processos. Sendo essa a essência da organização capitalista de produção, uma economia nacional que se articule com esse universo maior de forma estática, sob a premissa das vantagens comparativas permanentes, estará realizando uma inserção "imperfeita”, não competitiva. $\mathrm{Na}$ hipótese de um relativo declínio, como aventado neste ensaio, do "grande comércio" mundial de manufaturas, a inserção almejada deve deixar aberta a possibilidade de se evoluir rapidamente do ideal de global trader para o de global investor.

Em outras palavras, devem os agentes econômicos nacionais adquirir as características essenciais do modo histórico maior a que se pretende articular, o que supõe, como se viu, a adoção de uma nova cultura empresarial. Ao não satisfazer estas condições, a "parte” que se insere no universo maior terá aspectos de um “corpo estranho”, arrastada ao sabor das injunções e incapaz de promover seu próprio espaço.

Fevereiro de 1999 